\title{
Appearance Type Code
}

National Cancer Institute

\section{Source}

National Cancer Institute. Appearance Type Code. NCI Thesaurus. Code C93506.

A coded value specifying the appearance of an entity. 